\title{
EVALUASI PENGELOLAAN JEMBATAN PENYEBERANGAN MULTIGUNA TANAH ABANG
}

\author{
Hari Azhari ${ }^{1)}$, Parino Rahardjo ${ }^{2)}$ \\ 1) Program Studi S1 PWK, Fakultas Teknik, Universitas Tarumanagara, haria.pwk@stu.untar.ac.id \\ 2) Program Studi S1 PWK, Fakultas Teknik, Universitas Tarumanagara, parinor19@gmail.com
}

\begin{abstract}
Abstrak
Jembatan Penyeberangan Multiguna Tanah Abang merupakan suatu bangunan yang terletak di kawasan Pasar Tanah Abang tepatnya di Kelurahan Kampung Bali, kecamatan Tanah Abang, Jakarta Pusat. Jematan Penyeberangan Multiguna Tanah Abang dibangun atas dasar relokasi para pedagang kaki lima pada kawasan Tanah Abang yang dibangun oleh PD Sarana Jaya dan Pemerintah DKI Jakarta. Pembangunan Jembatan Penyeberangan Multiguna Tanah Abang ini didasari oleh instruksi Gubernur DKI Jakarta yaitu Anies Baswedan guna untuk merelokasi para pedagang kaki lima yang menjamur dan kerap selalu membuat kemacetan pada Jalan Jatibaru Raya. Jembatan Penyeberangan Multiguna Tanah Abang dibangun pada bulan Agustus tahun 2018 dan mulai dioperasikan dengan masa percobaan pada bulan Desember tahun 2018. Dengan adanya Jembatan Penyeberangan Multiguna, menjadikannya sebagai kawasan perdagangan baru pada kawasan pasar Tanah Abang yang terhubung langsung dengan beberapa moda Transportasi dan juga kawasan pasar Tanah Abang lainnya. Namun kawasan Jembatan Penyeberangan Multiguna Tanah Abang ini masih memiliki kekurangan pada segi pengelolaannya, terutama pada ketesediaan fasilitas seperti toilet, tempat duduk dan juga charging booth serta pada segi kebersihan dan keamanannya. Penulis melakukan beberapa analisis seperti analisis kebijkana, analisis lokasi, analisis tapak, analisis best practies serta analisis presepsi dan preferensi pengunjung sehingga menghasilkan usulan dan rencana evaluasi pengelolaan pada kawasan Jembatan Penyeberangan Multiguna Tanah Abang.
\end{abstract}

Kata kunci: evaluasi; jembatan; pengelolaan

\begin{abstract}
The Tanah Abang Multiway Skybridge is a building located at Tanah Abang Market Area, precisely in Kampung Bali Village, Tanah Abang District, Central Jakarta. The Tanah Abang Multiway Skybridge was built on the basis of the relocation of street vendors in Tanah Abang Area, which was built by PD Saran Jaya and the Regional Government of DKI Jakarta. The construction of the Tanah Abang Multiway Skybridge is based on the instruction of the Governor of DKI Jakarta, Anies Baswedan, to relocate street vendor who are mushrooming and often create traffic jam on Jati Baru Raya Street. The Tanah Abang Multiway Skybridge was built in August 2018 and began operating on a trial period in December 2018. With The Tanah Abang Multiway Skybrigde in The Tanah Abang Area, it has become a new trending area in The Tanah Abang Market Area which is directly connected with several modes of transportation and also other Tanah Abang Market Areas. But The Tanah Abang Multiway Skybrigde Area still has shortcomings in terms of its management, especially on the availability of facilities such as toilets, seating and also the charging booth as well as in terms of cleaniliness and securities. The Author conducted several analyses such as policy analysis, location analysis, site analysis, best practies analysis and them analysis of perception and preference of visitors to produce proposals and the management evaluation plans at Tanah Abang Multiway Skybridge Area.
\end{abstract}

Keywords: evaluation; management; skybridge 


\section{PENDAHULUAN}

Daerah Khusus Ibukota Jakarta merupakan Ibukota Negara Indonesia. DKI Jakarta menjadi kota megapolitan yang padat karena memiliki tingkat pertumbuhan penduduk dan arus mobilitas menusia yang tinggi, baik dari masyarakat DKI Jakarta maupun dari masyarakat luar daerah sekitar yang menggantungkan hidup pada Kota Jakarta. DKI Jakarta terbagi menjadi 5 Kota Administrasi dan 1 Kabupaten Administrasi yaitu Jakarta Pusat, Jakarta Utara, Jakarta Selatan, Jakarta Barat, Jakarta Timur dan Kep.Seribu.

Pasar Tanah Abang merupakan suatu kawasan yang tekenal sebagai pusat perdagangan berbagai macam produk yang dijual secara grosir maupun eceran yang terletak di Kecamatan Tanah Abang Jakarta Pusat. Berbagai macam pilihan produk dan murahnya harga yang ditawarkan membuat tempat ini menjadi 'surga belanja' yang selalu didatangi banyak orang, baik dalam maupun luar negeri. Sebagai pusat pedagangan yang besar, menyebabkan wilayah di sekitar pasar Tanah Abang selalu mengalami kemacetan. Kemacetan yang terjadi disekitar wilayah Tanah Abang ini di sebabkan oleh meluapnya pedagang kaki lima hingga ke badan jalan, serta banyaknya angkutan umum yang berhenti tidak pada tempatnya. Upaya pemerintah DKI Jakarta atas kemacetan yang terus menerus terjadi di kawasan Tanah Abang yaitu dengan membangunnya Jembatan Penyeberangan Multiguna yang dibangun oleh PD Sarana jaya beserta dengan Pemerintah DKI Jakarta. Tujuannya yaitu untuk memindahkan pedagang kaki lima yang terus memenuhi badan jalan ke Jembatan penyeberangan Multiguna agar dapat mengurangi kemacetan yang sering terjadi.

Jembatan Penyeberangan Multiguna dibangun pada bulan Agustus tahun 2018 yang terletak di Jl. Jatibaru Raya, Tanah Abang. Memiliki panjang 386,4 meter dengan lebar 12,6 meter dan memiliki ketinggian 12 meter dari jalan. Terdapat 446 kios pada Jembatan Penyeberangan Multiguna Tanah Abang yang masing-masing memiliki ukuran 1,5 meter $\times 2$ meter. Jembatan penyeberangan Multiguna Tanah Abang ini terintegrasi dengan beberapa moda transportasi yang ada seperti KRL, Transjakarta dan angkutan umum Jaklingko serta terhubung juga dengan kawasan pasar Tanah Abang lainnya.

Rencana pengelolaan yang dimiliki pihak pengelola Jembatan Penyeberangan Multiguna saat ini ialah perubahan jam operasional kios yang sebelumnya pukul $08.00-16.00$ menjadi 08.00 - 18.00. Permasalahan yang timbul pada Jembatan Penyeberangan Multiguna Tanah Abang ialah ketersediaan fasilitas yang masih belum memadai, seperti contohnya pada penyediaan unit smart toilet yang sedikit, sehingga menyebabkan antrian yang berlebih pada fasilitas toilet dan juga menyebabkan kondisi toiler menjadi kotor dan kumuh. Kemudian pada ketersediaan fasilitas bangku yang sedikit menyebabkan para pengguna Jembatan kerap duduk pada lantai Jembatan, serta fasilitas Charging Booth yang ada pada Jembatan banyak yang tidak dapat digunakan, bahkan beberapa unitnya hanya terkunci sehingga fasilitas tersebut tidak dapat dinikmati oleh para pengunjung. Dengan demikian penulis tertarik untuk melakukan Evaluasi Pengelolaan terkait dengan jam operasional kios pada Jembatan Penyeberangan Multiguna yang berpengaruh terhadap jam operasional transportasi yang ada serta memaksimalkan pengelolaan terkait dengan fasilitas dan kebersihan yang saat ini ada pada Jembatan Penyeberangan Multiguna Tanah Abang

\section{KAJIAN LITERATUR}

\section{Definisi Evaluasi}

Menurut Kamus Besar Bahas Indonesia (1996) Evaluasi adalah penilaian. Menurut Wirawan (2012) Evaluasi adalah riset intuk mengumpulkan, menganalisis dan menyajikan informasi yang bermanfaat mengenai objek evaluasi. Kemudia menilainya dan membandingkan dengan indikator evaluasi dan hasilnya dipergunakan untuk mengambil keputusan mengenai objek evaluasi tersebut. 


\section{Pengertian Pengeloaan}

Pengelolaan berasal dari kata kelola, dalam Kamus Besar Bahasa Indonesia Kontemporer karangan Peter Salim dan Yenny Salim (2002) berarti memimpin, mengendalikan, mengatur dan mengusahakan supaya lebih baik, lebih maju dan sebagainya serta bertanggung jawab atas pekerjaan tertentu.

\section{Pengertian Pusat Perbelanjaan}

Menurut International Council of Shopping Centre (ICSC) pusat perbelanjaan adalah sekelompok lokasi usaha ritel dan usaha komersil lainnya yang direncanakan, dikembangkan, dimiliki dan dikelola sebagai property tunggal.

\section{Pengertian Jembatan Penyeberangan Orang (JPO)}

Menurut Kementrian PU (1995) jembatan penyeberangan orang adalah jembatan yang hanya diperuntukkan bagi lalu lintas pejalan kaki. Viaduct merupakan sebutan untuk jembatan yang melintas diatas jalan. Jembatan penyeberangan berfungsi untuk melewatkan jalan yang terputus karena adanya hambatan seperti saluran, sungai, kanal, selat, lembah, jalan dan rel kereta api.

\section{METODE}

Data yang dikumpulkan pada proses penelitian adalah data kebijakan kawasan Tanah Abang, data lokasi dan fasilitas Jembatan Penyeberangan Multiguna Tanah Abang, data jumlah pengunjung, data pengelolaan Jembatan Penyeberangan Multiguna dan Benchmarking. Teknik pengumpulan data yang dilakukan dalam penelitian ini terbagi atas metode pengumpulan data primer dan sekunder. Untuk metode pengumpulan data primer dilakukan dengan observasi/survei lapangan dan wawancara dengan pihak-pihak terkait. Sementara untuk metode pengumpulan data sekunder dilakukan dengan dokumentasi dan studi literatur.

Untuk analisis yang dilakukan dalam penelitian ini adalah analisis kebijkan terkait dengan rencana penataan pada kawasan Tanah Abang, analisis lokasi, analisis tapak, analaisis best practies dan analisis presepsi dan preferensi pengunjung. Alat analisis yang digunakan untuk menyelesaikan analisis tersebut adalah benchmarking, SWOT analisis, deskriptif, skala likert, diagram kartecius dan metode IPA.

\section{DISKUSI DAN HASIL}

\section{Analisis Kebijakan}

Berdasarkan kebijakan Pemerintah dan Instruksi Gubernur menurut arahan penataan pada kawasan Tanah Abang sebagai salah satu kawasan perdagangan tekstil berskala besar uang ada di Jakarta Pusat. Adapun rencana Pemerintah dan Instruksi gubernur ingin melakukan penataan pada Kawasan Tanah Abang yang memiliki skala perdagangan tekstil yang besar dan memiliki angkutan massal pada kawasan tersebut.

Namun pada kenyataannya, kebijakan tersebut belum sepenuhnya dilakukan. Dapat dilihat bahwa pada kawasan Tanah Abang hingga saat ini masih banyak terdapat pedangan kaki lima yang berjualan pada badan jalan dan juga beberapa angkutan umum yang masih terus berhenti tidak pada tempat yang telah di sediakan sehingga masih menyebabkan kemacetan pada kawasan Tanah Abang.

Harapannya, semoga kebijakan Pemerintah dan juga Instruksi Gubernur pada kawasan Tanah Abang dapat segera terleasasikan, sehingga kawasan Tanah Abang dapat terbebas dari pedagang kaki lima yang selalu menjamur pada badan jalan dan juga tidak adanya kemcetan yang selalu terjadi disebabkan oleh angkutan umum yang berhenti tidak pada tempatnya. Sehingga menjadikan kawasan Tanah Abang sebagai kawasan perdagangan tekstil berskala besar yang terbebas dari para pedagang kaki lima dan kemacetan serta memiliki berbagai moda angkutan massal 


\section{Analisis Lokasi}

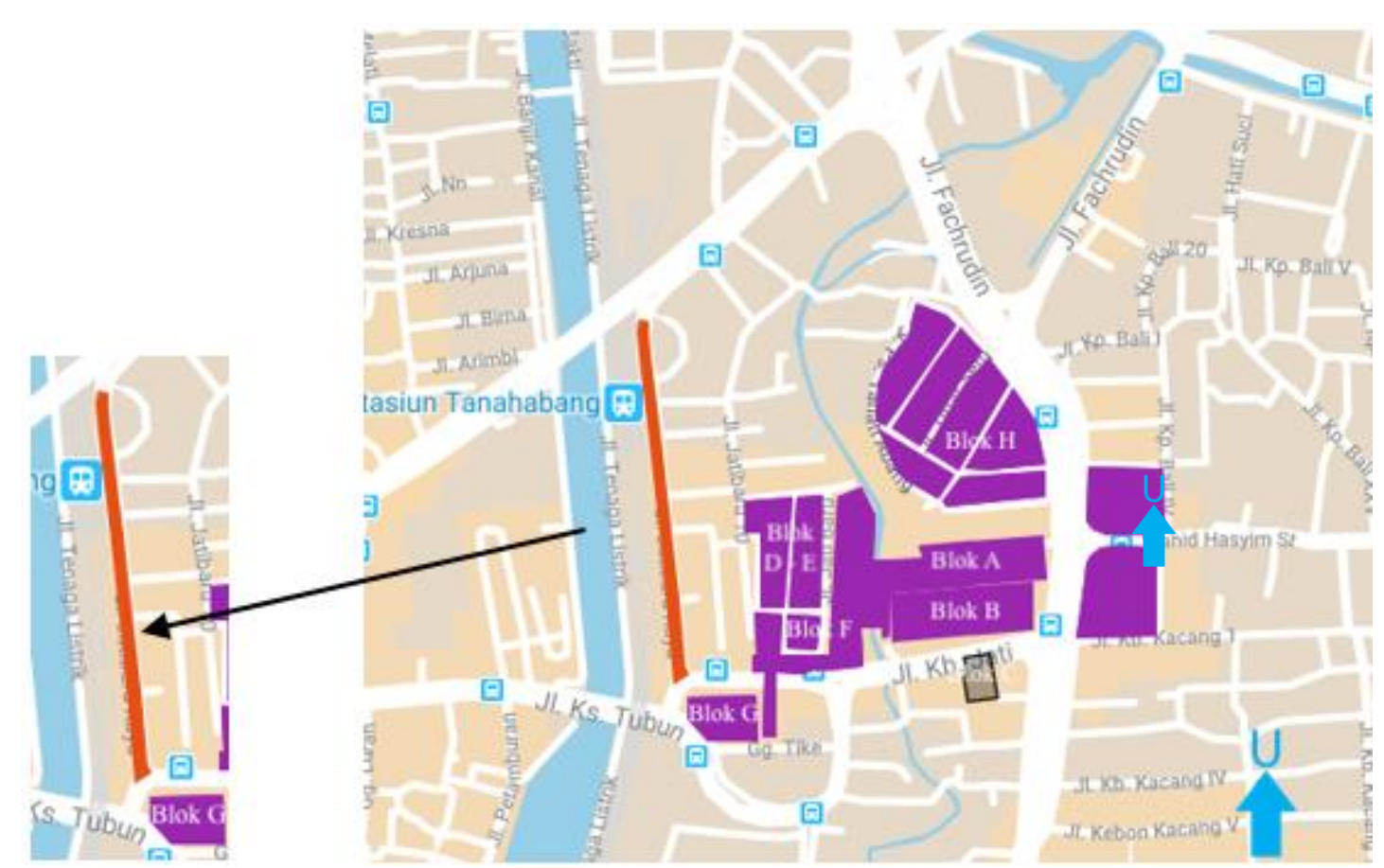

Gambar 1. Lokasi Jembatan Penyeberangan Multiguna Tanah Abang Sumber: Google Maps dan Penulis, 2019

Lokasi Jembatan Penyeberangan Multiguna yang terletak di pusat Kota Jakarta memberikan kemudahan pencapaian se Jabodetabek. Kawasan Jembatan Penyeberangan Multiguna Tanah Abang memiliki aksesibilitas yang mudah dijangkau, baik dengan transportasi umum seperti KRL, Transjakarta, Kopaja, metro Mini, Mikrolet maupun dengan kendaraan pribadi. Berikut ini adalah rute pencapaian untuk menuju Jembatan Penyeberangan Multiguna Tanah Abang dengan menggunakan kendaraan Pribadi:

Tabel 1. Akses menuju Jembatan Penyeberangan Multiguna Tanah Abang

\begin{tabular}{ll}
\hline \multicolumn{1}{c}{ Aksesibilitas } & \multicolumn{1}{c}{ Rute } \\
\hline Dari Tangerang & Jl. Tol Jakarta Merak - Jl. Tol Dalam Kota - \\
& Exit Tol Slipi - Jl. Slipi I - Jl. Jatibaru Raya \\
\hline Dari Bogor & Jl. Tol Jagorawi - Jl. Tol dalam Kota - Exit Tol \\
& Semanggi - Jl. Jend. Sudirman - Jl. K.H. Mas \\
& Mansyur - Jl. Jatibaru Raya \\
& \\
\hline Dari Bekasi & Jl. Tol Jakarta Bekasi - Jl. Tol dalam Kota - \\
& Exit Tol Semanggi - Jl. Jend. Sudirman - J. \\
& K.H. Mas Mansyur - Jl. Jatibaru Raya \\
\hline Dari Depok & Jl. Margonda Raya - Jl. Raya Lenteng Agung \\
& - Jl. Raya Pasar Minggu - Jl. Gatot Subroto \\
& - Jl. Jend. Sudirman - Jl. K.H. Mas Mansyur \\
& - Jl. Jatibaru Raya \\
\hline
\end{tabular}

Sumber: Penulis, 2019 


\section{Analisis Tapak}

Penggunaan Lahan Sekitar Tapak

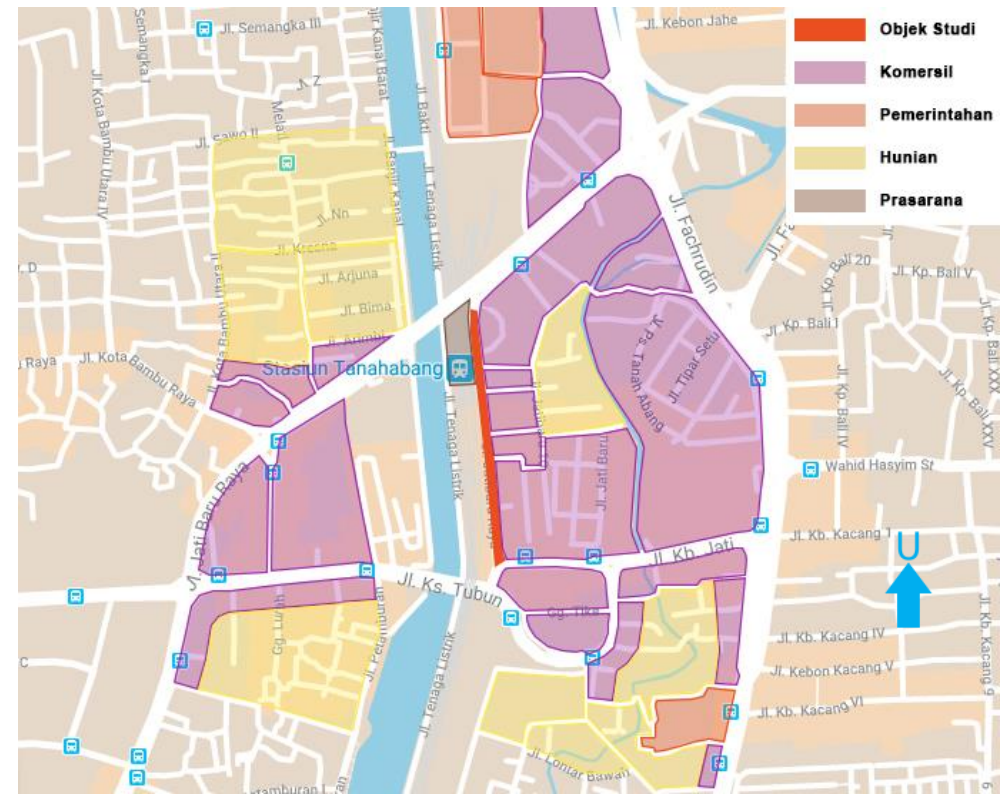

Gambar 2. Penggunaan Lahan Sekitar Tapak

Sumber: Google Maps dan Penulis, 2019

Penggunaan lahan sekitar kawasan Jembatan Penyeberangan Multiguna Tanah Abang merupakan kawasan komersil, yaitu pada kawasan tersebebut terdapat kawasan Tanah Abang lainnya seperti kawasan Tanah Abang blok A - G dan kawasan komersil pada sepanjang jalan K.H. Mas Mansyur. Pada kawasan Jembatan Penyeberangan Multiguna Tanah Abang juga terdapat kawasan pemerintahan, yaitu kantor Dinas Perhubungan dan kantor Lurah Kebon Kacang. Selain kawasan Komersil dan Pemerintahan, pada kawasan tersebut juga terdapat kawasan Hunian. Kawasan Hunian yang ada pada kawasan tersebut adalah kawasan Hunian kelas menengah bawah.

\section{Fasilitas Pada Jembatan Peyeberangan Multiguna Tanah Abang}

Terdapat fasilitas pada Jembatan Penyeberangan Multiguna Tanah Abang, yaitu smart toilet, charging booth dan tempat duduk. Terdapat 3 unit smart toilet pada Jembatan Penyeberangan Multiguna Tanah Abang, yang dimana pada masing-masing unit terdapat dua kamar toilet yang dibedakan penggunaannya yaitu untuk pria dan wanita. Namun dikarenakan jumlahnya yang sedikit, yaitu hanya 3 unit smart toilet, menyebabkan antrian yang selalu berlebih sehingga membuat kondisi smart toilet terkesan kumuh dan kotor.

Pada kawasan Jembatan Penyeberangan Multiguna Tanah Abang terdapat Charging Booth yang dapat digunakan secara gratis untuk para pengunjung. Namun sayangnya, banyak dari unit Charging Booth tersebut yang belum dapat digunakan dan bahkan hanya terkunci pada bagian box unitnya. Sehingga para pengunjung Jembatan Penyeberangan Multiguna tidak dapat menggunakan fasilitas tersebut.

Pada Jembatan Penyeberangan Multiguna Tanah Abang juga terdapat bangku yang dikhususkan untuk disabilitas. Tetapi pada kenyataannya, bangku tersebut tidak banyak digunakan oleh para disabilitas, melainkan oleh para pengguna kios atau bahkan pengunjung yang lelah berbelanja atau menunggu rekannya berbelanja. Sedikitnya unit bangku pada Jembatan Penyeberangan Multiguna Tanah Abang juga menyebabkan para pengunjung kerap duduk pada lantai atau bahkan menggunakan kursi lipat yang membuat kawasan Jembatan Penyeberangan Multiguna Tanah Abang terkesan kumuh dan tidak tertata. 


\section{Utilitas Pada Jembatan Penyeberangan Multiguna Tanah Abang}

Pada Jembatan Penyeberangan Multiguna Tanah Abang terdapat beberapa Utilitas, yaitu 22 unit CCTV yang digunakan untuk memantau setiap pergerakan yang ada pada kawasan Jembatan penyeberangan Multiguna Tanah Abang. Dengan keberadaan CCTV ini dapat memudahkan para petugas keamanan untuk terus memantau setiap pergerakan maupun jika suatu saat terjadi tindak criminal atau hal-hal yang mencurigakan pada kawasan Penyeberangan Multiguna Tanah Abang.

Selain CCTV, pada kawasan Jembatan Penyeberangan Multiguna Tanah Abng juga terdapat signage yang berupa arahan untuk menuju ke berbagai lokasi yang ada pada kawasan tersebut. Keberadaan signage pada kawasan Jembatan Penyeberangan Multiguna Tanah Abang sangat membantu dan berguna, sehingga para pengunjung yang dating dapat dengan mudah untuk menuju lokasi yang ini dituju.

\section{Analisis Best Practies}

Analisis ini dilakukan untuk mencari objek pembanding dari Jembatan Penyeberangan Multiguna Tanah Abang dengan memiliki konsep dan bangunan sejenis yang dapat dijadikan contoh terbaik agar dapat dijadikan acuan dalam melakukan evaluasi pengelolaan. Best Practies yang digunakan adalah Cihampelas Skywak yang terletak dibandung. Cihampelas merupakan salah satu tempat tujuan wisata berbelanja seperti pakaian, souvenir, kuliner dan juga modern market. Cihampelas yang merupakan salah satu tempat yang sering dikunjungi oleh banyak wisatawan menyebabkan banyaknya para pedagang kaki lima yang berjualan pada kawasan tersebut. Keberadaan para pedagang kaki lima tersebut kerap membuat kemacetan pada kawasn Cihampelas.

Upaya Pemerintah Kota Bandung untuk mengatasi masalah tersebut adalah dengan membangun Skywalk yang bertujuan untuk merelokasi para pedagang kaki lima sehingga dapat mengurai kemacetan yang kerap terjadi pada kawasan Cihampelas. Cihampelas Skywalk memiliki panjang 450 meter denganlebar 9 meter dan memiliki tinggi 4,6 meter dari permukaan jalan. Terdapat 197 unit kios pada Cihampelas Skywalk yang dibangun pada tahun 2014 dan telah diresmikan dan digunakan pada bulan februari 2017.

Tabel 2. Perbandingan Best Practies

\begin{tabular}{|c|c|c|c|}
\hline \multicolumn{4}{|c|}{ Terkait Dengan Kebijakan } \\
\hline No & Best Practies & Lokasi Studi & Rekomendasi \\
\hline 1 & $\begin{array}{l}\text { Upaya Pemerintah Kota } \\
\text { Bandung dalam } \\
\text { membangun Cihampelas } \\
\text { Skywalk tidak hanya } \\
\text { untuk merevitalisasi PKL, } \\
\text { melainkan menjadikan } \\
\text { ikon wisata Kota } \\
\text { Bandung }\end{array}$ & $\begin{array}{l}\text { Upaya Pemerintah DKI } \\
\text { Jakarta dalam } \\
\text { membangun Jembatan } \\
\text { penyeberangan } \\
\text { Multgiuna Tanah } \\
\text { Abang ialah untuk } \\
\text { merevitalisasi PKL yang } \\
\text { ada pada kawasan } \\
\text { tersebut }\end{array}$ & $\begin{array}{l}\text { Upaya Pemerintah DKI Jakarta } \\
\text { dalam membangun Jembatan } \\
\text { Penyeberangan Multiguna Tanah } \\
\text { Abang tidak hanya sebatas } \\
\text { merevitalisasi PKL, melainkan } \\
\text { untuk menciptakan aktivitas- } \\
\text { aktivitas baru sehingga kawasan } \\
\text { tersebut dapat menjadi pusat } \\
\text { kegiatan baru pada kawasan } \\
\text { Tanah Abang yang terhubung } \\
\text { langsung dengan beberapa moda } \\
\text { Transportasi. }\end{array}$ \\
\hline
\end{tabular}




\begin{tabular}{|c|c|c|c|}
\hline \multicolumn{4}{|c|}{$\begin{array}{l}\text {...lanjutan } \\
\text { Terkait Dengan Program Pemerintah }\end{array}$} \\
\hline No & Best Practies & Lokasi Studi & Rekomendasi \\
\hline 1 & $\begin{array}{l}\text { Pada Cihampelas } \\
\text { Skywak terdapat } 1 \text { unit } \\
\text { lift untuk memudahkan } \\
\text { para wisatawan atau } \\
\text { penggunan } \quad \text { untuk } \\
\text { menuju Cihampelas } \\
\text { Skywalk }\end{array}$ & $\begin{array}{l}\text { Tidak ada unit lift pada } \\
\text { Jembatan } \\
\text { Penyeberangan } \\
\text { Multiguna Tanah } \\
\text { Abang, malainkan } \\
\text { hanya terdapat tangga } \\
\text { untuk akses menuju } \\
\text { Jembatan } \\
\text { Penyeberangan } \\
\text { Multiguna Tanah } \\
\text { Abang }\end{array}$ & $\begin{array}{l}\text { Pemerintah DKI Jakarta dapat } \\
\text { menambahnya fasilitas lift pada } \\
\text { Jembatan Penyeberangan } \\
\text { Multiguna Tanah Abang untuk } \\
\text { memudahkan akses menuju } \\
\text { Jembatan Penyeberangan } \\
\text { Multiguna Tanah Abang }\end{array}$ \\
\hline 2 & $\begin{array}{l}\text { Terdapat Toilet yang } \\
\text { dapat digunakan untuk } \\
\text { para Difabel pada } \\
\text { Cihampelas Skywalk }\end{array}$ & $\begin{array}{l}\text { Hanya terdapat smart } \\
\text { toilet pada Jembatan } \\
\text { Penyeberangan } \\
\text { Multiguna Tanah } \\
\text { Abang }\end{array}$ & $\begin{array}{l}\text { Menambahkan fasilitas toilet } \\
\text { khusus Difabel, sehingga dapat } \\
\text { nyaman digunakan untuk para } \\
\text { Difabel }\end{array}$ \\
\hline 3 & $\begin{array}{l}\text { Terdapat banyak fasilitas } \\
\text { bangku yang nyaman di } \\
\text { sertai dengan adanya } \\
\text { taman dan penghijauan } \\
\text { padar Cihampelas } \\
\text { Skywalk }\end{array}$ & $\begin{array}{l}\text { Terdapat beberapa } \\
\text { fasilitas bangku yang di } \\
\text { khususkan untuk } \\
\text { Disabilitas dan tidak } \\
\text { adanya } \\
\text { penghijauan/taman } \\
\text { pada Jembatan } \\
\begin{array}{ll}\text { Penyeberangan } \\
\text { Multiguna Tanah } \\
\text { Abang }\end{array} \\
\end{array}$ & $\begin{array}{l}\text { Menambahkan fasilitas bangku } \\
\text { untuk para pengguna Jembatan } \\
\text { Penyeberangan Multguna Tanah } \\
\text { Abang sehingga dapat menjadi } \\
\text { tempat untuk beristirahat serta } \\
\text { memperhatian penghijauan yang } \\
\text { hingga saat ini tidak ada pada } \\
\text { kawasan Jembatan } \\
\text { Penyeberangan Multiguna Tanah } \\
\text { Abang }\end{array}$ \\
\hline 4 & $\begin{array}{l}\text { Dinas Koperasi dan } \\
\text { usaha Kecil Menengah } \\
\text { (KUKM) Kota Bandung } \\
\text { menggelar acara } \\
\text { Bandung Lautan Musik } \\
\text { untuk memperingati dan } \\
\text { merayakan berdirinya } \\
\text { Cihampelas Skywalk } \\
\text { sebagai infrastruktur } \\
\text { yang menjadi ikon } \\
\text { wisata Kota Bandung }\end{array}$ & $\begin{array}{lr}\text { Tidak adanya rencana } \\
\text { dari pemerintah DKI } \\
\text { Jakarta dalam } \\
\text { memperingati dan } \\
\text { merayakan berdirinya } \\
\text { Jembatan } \\
\text { Penyeberangan } \\
\text { Multiguna Tanah } \\
\text { Abang }\end{array}$ & $\begin{array}{l}\text { Membuat serangkaian acara } \\
\text { dalam memperingati dan } \\
\text { merayakan berdirinya Jembatan } \\
\text { Penyeberagan Multiguna Tanah } \\
\text { Abang sehingga kedepannya akan } \\
\text { dapat menciptakan aktifitas ruang } \\
\text { public pada Jembatan } \\
\text { Penyeberangan Multiguna Tanah } \\
\text { Abang }\end{array}$ \\
\hline 5 & $\begin{array}{l}\text { Jam operasional pada } \\
\text { Cihampelas Skywalk } \\
\text { ialah } 08.00-22.00\end{array}$ & $\begin{array}{l}\text { Jam operasional pada } \\
\text { Jemabatan } \\
\text { Penyeberangan } \\
\text { Multiguna Tanah } \\
\text { Abang ialah } 08.00 \text { - } \\
18.00\end{array}$ & $\begin{array}{l}\text { Menambah jam operasional pada } \\
\text { Jembatan Penyeberangan } \\
\text { Multiguna Tanah Abang guna } \\
\text { untuk meningkatkan aktivitas jual } \\
\text { beli dan pendapatan para } \\
\text { pedagang }\end{array}$ \\
\hline
\end{tabular}

Sumber: Penulis, 2019 


\section{Analisis Presepsi dan Preferensi Pengunjung}

Analisis ini dilakukan untuk mengetahui presepsi dari pengunjung yang dating ke Jembatan Penyeberangan Multiguna Tanah Abang dengan menyebarkan sebanyak 100 kuesioner. Untuk mengetahui lebih dalam mengenai presepsi dan preferensi pengunjung pada Jembatan Penyeberangan Multiguna Tanah Abang, maka akan dikelompokkan beberapa bagian kuesioner: Profil dan karakteristik pengunjung

a. Jenis Kelamin

Dalam penyebaran kuesioner pada Jembatan penyebernagan Multiguna Tanah Abang mendapatkan hasil jenis kelamin pengunjung yang didominasi oleh perempuan sebesar $64 \%$ sedangkan untuk laku-laki sebesar $36 \%$

b. Usia

Dalam penyebaran kuesioner pada Jembatan Penyeberangan Multiguna Tanah Abang, pengunjung/pengguna yang datang didominasi dengan usia 26-40 Tahun yaitu sebesar $51 \%$ kemudian usia >40 Tahun sebesar 33\% dan usia 17-25 Tahun sebesar $16 \%$.

c. Tempat Tinggal

Dalam penyebaran kuesioner pada Jembatan Penyeberangan Multiguna Tanah Abang, pengunjung/pengguna yang datang didominasi oleh masyarakat yang berasal dari Bogor/Depok/Bekasi yaitu sebesar 38\%. Kemudian pengunjung/pengguna Jembatan Penyeberangan Multiguna Tanah Abang juga di dominasi oleh masyarakat yang berasal dari Tangerang yaitu sebesar $32 \%$ lalu diikuti juga oleh masyarakat yang berasal dari Jakarta yaitu sebesar $28 \%$ serta $2 \%$ untuk masyarakat yang datang dari kota lainnya.

d. Pendidikan Terakhir

Dalam hal pendidikan terakhir, para pengunjung/pengguna yang datang ke Jembatan Penyeberangan Multiguna Tanah Abang di dominasi oleh Sarjana yaitu sebesar 57\%. Kemudian pengunjung/pengguna Jembatan Penyeberangan Multiguna Tanah Abang juga di dominasi oleh Diploma yaitu sebesar 23\% dan diikuti oleh SMA/SMK sebesar $20 \%$.

e. Pekerjaan

Dalam hal pekerjaan, para pengguna/pengunjung Jembatan Penyeberangan Multiguna Tanah Abang didominasi oleh Pekerjaan Lain yaitu sebesar $45 \%$. Selain itu juga terdapat Wiraswasta sebesar $30 \%$ yang diikuti oleh Wirausaha sebesar $16 \%$ dan Pelajar sebesar $9 \%$.

f. Pendapatan Perbulan

Untuk pendapatan perbulan para pengunjung/pengguna Jembatan penyeberangan Multiguna Tanah Abang didominasi oleh pendapatan Rp. 1.500.000 - Rp. 4.000.000 sebesar $76 \%$. Lalu kemudian ada juga pendapatan $>$ Rp. 4.000 .000 sebesar $17 \%$ dan diikuti dengan pendapatan $<$ Rp. 1.500 .000 sebesar $7 \%$.

Tujuan kunjungan

a. Moda Transportasi Yang Digunakan

Pada hasil kuesioner yang disebar pada Jembatan Penyeberangan Multiguna Tanah Abang, mayoritas pengunjung/pengguna yang datang didominasi oleh pengguna pendaraan umum yaitu sebesar $88 \%$. Kemudian terdapat $10 \%$ pada pengguna/pengunjung yang datang menggunakan kendaraan online dan juga $2 \%$ untuk pengguna/pengunjung yang datang menggunakan kendaraan roda dua.

b. Banyaknya Kunjungan

Pada bagian ini, terlihat bahwa pengguna/pengunjung yang datang ke Jembatan penyebrangan Multiguna Tanah Abang didominasi oleh $>3$ kali sebesar $52 \%$. Kemudian pada 2 kali memiliki angka sebesar $25 \%$ dan diikuti oleh 1 kali dengan angka sebesar $23 \%$.

c. Waktu Berkunjung

Pada bagian waktu berkunjung, dapat dilihat bahwa para pengunjung/pengguna Jembatan Penyeberangan Multiguna Tanah Abang didominasi oleh weekday dengan angka sebesar $65 \%$ yang kemudian diikuti oleh weekend dengan angka sebesar $31 \%$ dan pada waktu tertentu dengan angka sebesar $4 \%$. 


\section{d. Rekan Kunjungan}

Pada bagian rekan kunjungan, dapat dilihat bahwa para pengunjung/pengguna Jembatan Penyeberangan Multiguna Tanah Abang didominasi oleh yang datang sendiri dengan angka sebesar 45\%. Lalu kemudian ada juga yang datang bersama dengan saudara/keluarga yang memiliki angka sebesar $29 \%$ dan yang terakhir adalah para pengunjung/pengguna yang datang bersama teman yaitu sebesar $26 \%$.

e. Tujuan Kunjungan

Tujuan para pengunjung/pengguna pada Jembatan penyeberangan Multiguna Tanah Abang didominasi oleh yang ingin berbelanja pada Jembaatan Penyeberangan Multiguna Tanah Abang, yaitu sebesar $41 \%$. Kemudian para pengunjung/poengguna Jembatan Penyeberangan Multiguna Tanah Abang juga didominasi oleh yang melintas menuju kawasan Tanah Abang lainnya yaitu dengan angka sebesar $26 \%$. Para pengunjung/pengguna yang hanya melalukan titik transit kendaraan umum pada Jembatan Penyeberangan Multiguna Tanah Abang memiliki angka sebesar $24 \%$ yang diikuti dengan tujuan lainnya yaitu sebesar $9 \%$.

f. Durasi Kunjungan

Durasi kunjungan para pengunjung/pengguna Jembatan Penyeberangan Multiguna Tanah Abang didominasi oleh mereka yang hanya berada $<1$ Jam dengan angka sebesar $54 \%$ kemudian para pengunjung/pengguna yang berada di Jembatan Penyeberangan Multiguna Tanah Abang dengan durasi 1-3 Jam memiliki angka sebesar $46 \%$.

g. Pengeluaran Saat Kunjungan

Pengeluaran para pengungjung/pengguna yang ada pada Jembatan Penyeberangan Multiguna Tanah Abang didominasi oleh mereka yang hanya mengeluarkan <Rp. 100.000 dengan angka sebesar 54\% dan diikuti oleh mereka yang mengeluarkan Rp. $100.001-\mathrm{Rp}$. 500.000 dengan angka sebesar $46 \%$.

\section{Preferensi dan Prepsi Pengunjung}

a. Preferensi Pengunjung

Tabel 3. Fasilitas Yang Perlu Ditambah

\begin{tabular}{lcc}
\hline \multicolumn{1}{c}{ Aspek } & Total skor & Peringkat \\
\hline Penambahan penghijauan & 391 & 1 \\
\hline Penambahan fasilitas bangu/tempat peristirahatan & 390 & 2 \\
\hline Penambahan jam operasional kios & 390 & 3 \\
\hline Penambahan unit smart toilet & 387 & 4 \\
\hline Penambahan penjual makanan/minuman & 377 & 5 \\
\hline Penambahan Vending Machine (mesin jual otomatis) & 366 & 6 \\
\hline Penambahan mesin ATM & 365 & 7 \\
\hline
\end{tabular}

Sumber: Penulis, 2019

Dapat dilihat pada tabel diatas, nilai terbanyak fasilitas yang perlu ditambahkan berdasarkan pilihan responden yaitu penambahan penghijauan pada kawasan Jembatan Penyeberangan Multiguna Tanah Abang. Lalu kemudian pada peringkat kedua yaitu penambahan fasilitas bangku/tempat beristirahat dan pada peringkat ketiga yaitu penambahannya jam operasional kios yang ada pada Jembatan Penyeberangan Multiguna Tanah Abang. 
b. Presepsi Pengunjung

Tabel 4. Tingkat Kesesuaian

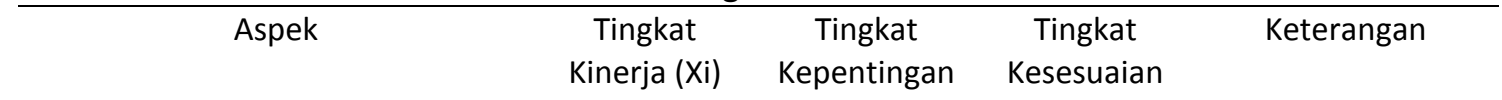

(Yi)

\begin{tabular}{lcccc}
\hline Aksesibilitas menuju JPM & 3,96 & 4 & 99,0 & Pertahankan \\
\hline Ketersediaan transportasi umum & 3,97 & 4 & 99,3 & Pertahankan \\
\hline Kondisi JPM & 3,53 & 3,44 & 102,6 & Pertahankan \\
\hline Kondisi kios & 3,6 & 3,65 & 98,6 & Pertahankan \\
\hline Kondisi smart toilet & 2,69 & 3,5 & 76,9 & Perlu ditingkatkan \\
\hline Kondisi bangku & 2,67 & 3,72 & 71,8 & Perlu ditingkatkan \\
\hline Kondisi charging booth & 2,85 & 4 & 71,3 & Perlu ditingkatkan \\
\hline Kondisi air bersih & 3,69 & 3,88 & 95,1 & Pertahankan \\
\hline Kondisi penerangan JPM & 3,21 & 3,37 & 95,3 & Pertahankan \\
\hline Kondisi kebersihan & 2,44 & 4 & 61,0 & Perlu ditingkatkan \\
\hline Kondisi keamanan & 2,69 & 4 & 67,0 & Perlu ditingkatkan \\
\hline Total & 35,3 & 41,56 & 938,0 & \\
\hline Rata-rata & 3,21 & 3,8 & 85,27 &
\end{tabular}

Sumber: Penulis, 2019

Dapat dilihat pada tabel diatas bahwa terdapat beberapa aspek yang perlu ditingkatkan kinerjanya dikarenakan skornya yang rendah namun memiliki harapan yang tinggi oleh responden, seperti pada aspek kondisi smart toilet, kondisi bangku, kondisi charging booth, kondisi kebersihan serta kondisi kemanan pada Jembatan Penyeberangan Multgiuna Tanah Abang. Nilai rata-rata dari tingkat kinerja (Xi) dan tingkat kepentingan (Yi) akan dijadikan batasan untuk diagram cartecius untuk kuadran I, II, III dan IV. Untuk tingkat kinerja kan berada pada koordinat $\mathrm{X}$ dan untuk tingkat kepentingan akan berada pada koordinat $\mathrm{Y}$.

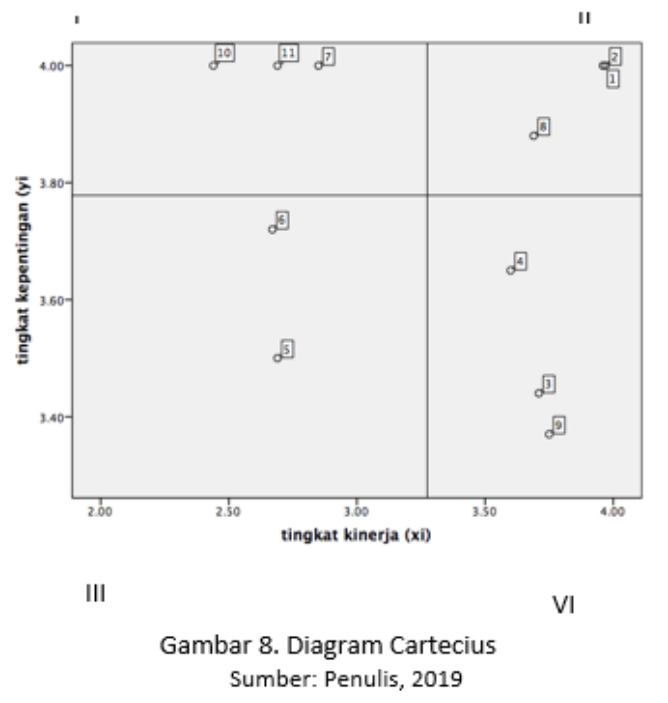




\section{Kuadran I (concentrate here)}

Kuadran I memiliki arti prioritas utama, aspek yang berada di kuadran I harus ditingkatkan kinerjanya oleh pihak pengelola Jembatan Penyeberangan Multiguna Tanah Abang dikarenakan aspek tersebut belum dijalankan dengan baik. Hal ini dapat dilihat dari tingginya tingkat kepentingan namun tingkat kinerjanya rendah. Berikut merupakan aspek-aspek yang berada di dalam kuadran I:

a. Kondisi charging booth pada no. 7

b. Kondisi kebersihan pada no. 10

c. Kondisi keamanan pada no. 11

Kuadran II (keep up the good work)

Kuadran II memiliki arti yaitu setiap aspek yang berada di kuadran ini harus dipertahankan, dikarenakan dapat dilihat dari tingkat kinerjanya yang tinggi dan tingkat kepentingannya yang juga tinggi. Berikut merupakan aspek-aspek yang berada di dalam kuadwan II :

a. Aksesibilitas menuju JPM pada no. 1

b. Ketersediaan transportasi umum pada no. 2

c. Kondisi air bersih pada no. 8

Kuadran III (low priority)

Kuadran III memiliki arti prioritas rendah dikarenakan memiliki tingkat kepentingan yang rendah bagi pengunjung. Hal ini dapat dilihat dari rendahnya tingkat kinerja dan tingkat keoentingannya. Berikut merupakan aspek-aspek yang berada di dalam kuadran III :

a. Kondisi smart toilet pada no. 5

b. Kondisi bangku pada no. 6 Kuadran VI (possible overkill)

Kuadran IV memiliki arti yang berlebihan dikarenakan dianggap tidak penting oleh pengunjung namun dijalankan dengan baik oleh pengelola Jembatan Penyeberangan Multiguna Tanah Abang. Hal ini dapat dilihat dari tingginya tingkat kinerja namum rendahnya tingkat kepentingan. Berikut merupakan aspek-aspek yang berada di dalam kuadran IV :

a. Kondisi JPM pada no. 3

b. Kondisi kios pada no. 4

c. Kondisi penerangan JPM pada no. 9

\section{KESIMPULAN DAN SARAN}

\section{Kesimpulan}

Dari hasil analisis yang telah dilakukan pada bab sebelumnya, maka dapat disimpulkan:

a. Jembatan Penyeberangan Multiguna Tanah Abang merupakan salah satu bangunan yang menghubungkan beberapa kawasan yang ada pada kawasan pasar Tanah Abang dan terintegrasi langsung dengan beberapa moda tranpsortasi massal. Dibangun atas dasar relokasi para pedangan kaki lima yang selalu menjamur dan membuat kemacetan pada kawasan Tanah Abang sehingga menjadikan Jembatan Penyeberangan Multiguna Tanah Abang sebagai pusat kegiatan berbelanja baru pada kawasan pasar Tanah Abang hingga JABODETABEK.

b. Potensi yang ada pada kawasan Jembatan Penyeberangan Multiguna Tanah Abang adalah kemudahan menuju lokasi baik menggunakan kendaraan pribadi maupun kendaraan umum dikarenakan lokasinya yang cukup strategis berada di pusat kegiatan Jakarta Pusat. Namun, Jembatan Penyeberangan Multiguna Tanah Abang masih memiliki banyak kekurangan terutama pada segi pengelolaan, yaitu kurangnya fasilitas-fasilitas penunjang.

c. Berdasarkan analisis presepsi pengunjung, dapat terlihat bahwa Jembatan Penyeberangan Multiguna Tanah Abang masih memiliki banyak kekurangan terutama pada segi pengelolaan, yaitu kurangnya beberapa fasilitas penunjang seperti tempat duduk, charging booth, unit smart toilet serta kebersihan dan keamana yang masih belum masksimal. 


\section{Saran}

Dari hasil analisis yang telah dilakukan pada bab sebelumnya, maka dapat disimpulkan:

a. Bagi pengelola

- Menambah beberapa fasilitas seperti yang diinginkan para responden saat penyebaran kuesioner yaitu berupa penghijauan pada kawasan Jembatan Penyeberangan Multiguna Tanah Abang, penambahan fasilitas bangku, fasilitas smart toilet serta mengoperasikan fasilitas charging booth yang tersedia.

- Merubah jam operasional kios yang sebelumnya hanya sampai pukul 17.00 menjadi hingga pukul 22.00, dikarenakan Jembatan Penyeberangan Multiguna Tanah Abang yang terintegrasi dengan beberapa moda transportasi yang ada dan juga jam pengoperasian Jembatan itu sendiri yang beroperasi hingga pukul 23.00 sehingga memberikan potensi kepada pada pelaku usaha yang ada pada kawasn tersebut.

- Melibatkan peran masyarakat sekitar dalam pengelolaan Jembatan Penyebrangan Multiguna Tanah Abang dengan cara me-rekruit mereka sebagai tenaga kerja, sehingga dapat melakukan sosialisasi tentang kawasan tersebut kepada masyarakat.

b. Bagi masyarakat dan pengunjung/pengguna

Agar selalu dapat bekerjasama dalam menjaga lingkungan sekitar serta dapat menaati peraturan yang ada di Jembatan Penyebrangan Multiguna Tanah Abang sehingga terciptanya kawasan yang tertib dan terjaga kebersihannya.

\section{REFERENSI}

George R. T. (2006). Prinsip-Prinsip Manajemen. Jakarta: Bumi Aksara.

Handoko, T. H. (1997). Manajemen Sumber Daya Manusia. Yogyakarta: Liberty.

Handyaningrat, S. (1997). Pengantar Studi Administrasi dan Management. Jakarta: Gunung Agung.

Lynda, W. K. N., Tong, K. W. (2005). 4 Langkah Penting Dalam Manajemen Pusat Perbelanjaan Asia. PT. Bhuana Ilmu Populer.

Rustiadi, E. (2008). Argopolitan, Strategi Pengembangan Pusat Pertumbuhan Pada Kawasan Perdesaan. Jakarta: Crestpent Press.

Salim, P dan Salim, Y. (2002). Kamus Bahasa Indonesia Kontemporer. Jakarta: Modern English Press.

Sobri. Dkk. (2009). Pengelolaan Pendidikan. Yogyakarta: Multi Pressindo. 